\title{
Conexões
}

\section{Análise de atos de currículo na educação física em escolas da rede municipal de Simão Dias - SE e Paripiranga - BA}

Libni David de Santana Macêdo ${ }^{1}$ Tiago de Melo Ramos ${ }^{1}$ Thaís Almeida Purificação ${ }^{1}$ Marcos Garcia Neira ${ }^{2}$

\section{RESUMO}

Atos de Currículo se constituem como toda e qualquer ação curricular planejada e desenvolvida pelos atores educacionais. Na Educação Física, estes vêm sendo motivados e influenciados pelas teorias curriculares tradicionais, crítica e pós-critica. Este trabalho surge a partir das inquietações pautadas em quais teorias curriculares estão vinculados os Atos de Currículo na Educação Física escolar no Ensino Fundamental II em escolas da Bahia e de Sergipe. Objetivamos analisar os planos de ensino da disciplina Educação Física, buscando vestígios das correntes teóricas. A metodologia é caracterizada como pesquisa de abordagem qualitativa do tipo documental. Analisamos o conteúdo por categoria. O objeto de estudo foram os planos de ensino de dois professores (P1 e P2), do $6^{\circ}$ e $9^{\circ}$ ano de duas escolas (E1 e E2). Os resultados apontam certa dificuldade na organização dos planos. Ambos apontam para a repetição dos esportes coletivos como temas dominantes, pautados principalmente em concepções tradicionais do currículo, concernindo à Educação Física escolar um papel reducionista de fomentar corpos biologicamente harmoniosos para o lazer, o trabalho e a aprendizagem de outros conhecimentos. Outro traço é a falta de progressão dos conteúdos a serem ensinados.

Palavras-chave: Educação Física escolar. Atos de Currículo. Teorias curriculares.

\footnotetext{
${ }^{1}$ Centro Universitário Ages

${ }^{2}$ Universidade de São Paulo Recebido em: 30 set. 2017 


\section{Analysis of curriculum acts in physical education in schools of the municipal network of Simão Dias - SE and Paripiranga-BA}

\section{Abstract}

Curriculum Acts constitute as any and all curricular action planned and developed by educational actors. In Physical Education, these have been motivated and influenced by the traditional curricular theories, critical and post-critical. This work arises from the restlessness based on which curricular theories are linked the Curricular Acts in Physical Education in elementary school in schools in Simão Dias/SE and Paripiranga/BA. We aim to analyze the teaching plans of Physical Education, looking for traces of theoretical currents. The methodology is described as qualitative research of the documental type. We analyzed the content by category. The study object was teaching plans of two teachers (T1 and T2), from 6th and 9th grade of two schools (S1 and S2). The results indicate a certain difficulty in the organization of the plans. Both point to the repetition of collective sports as dominant themes, based mainly on traditional conceptions of the curriculum. Concerning to the School Physical Education a reductionist role of fomenting biologically harmonious bodies for the leisure, the work and the learning of other knowledge. Another trait is the lack of progression of the contents to be taught

Keywords: School Physical Education. Curriculum Acts. Curricular theories.

\section{Análisis de actos de currículo en la educación física en escuelas de la red municipal de Simón Días - SE y Paripiranga - BA}

\section{RESUMEN}

Actos de currículo se constituyen como toda y cualquier acción planeada y desarrolada por los actores educativos. En la Educación Física, estos viene siendo motivados y influenciados por las teorías curricuares tradicionales crítica e postcrítica. Este trabajo se presenta a partir de las inquietudes pautadas em qué teorías están vinculados los Actos de Currículo en la Educación Física escolar em la enseñanza fundamental II en las escuelas em Bahía y Sergipe. Objetivamos analizar los planes de enseñanza de la disicplina Educación Física, buscando vestígios de las corrientes teóricas. Lá metodologia caracterizadora como busquéda de 
enfoque cualitativa del tipo documental. Analizamos el contenido por categoria. El objeto de estudio fueron los planes de enseñanza de dos profesores (P1 y P2), $6^{\circ}$ y $9^{\circ}$ año de dos escuelas(E1 y E2). Los resultados apuntan cierta dificultad em la organización de los planes. Los dos apuntan para la repetición de los desportes colectivos como temas dominantes, pautados principalmente en concepciones tradicionales del currículo. Com respecto a la Educación Física escolar uno papel reduccionista de fomentar cuerpos biológicamente armonizados para el ocio, el trabajo y el aprendizage de otros conocimientos. Outro trazado es la falta de progressión de los contenidos a ser enseñados.

Palabras Clave: Educación Física. Actos de Currículo. Teorías de Currículo. 


\section{INTRODUÇÃO}

A história da Educação Física escolar no Brasil é marcada por diversas mudanças no que diz respeito à concepção curricular, dentre estas, destacamos as concepções tradicionais, críticas e, mais recentemente, a pós-crítica (BARBIERI et al, 2008). Estas diferentes correntes têm ação direta nos Atos de Currículo deste componente nas escolas, principalmente no direcionamento dos conhecimentos para cada etapa da educação básica.

Autores como Nunes e Rúbio (2008), Neira e Nunes (2014) e Neira (2015) têm dado significativas contribuições nas discussões acerca do currículo e suas diferentes concepções na Educação Física escolar. Além desses, curriculistas como Gimeno Sacristán, Celso Vasconcellos e Roberto Macedo compõem a base para a discussão sobre currículo e seus atos no presente estudo, partindo de uma compreensão mais generalista, para posterior aprofundamento na Educação Física. Para isso, compreenderemos o currículo tal como ele é manifesto na escola, vislumbrando o olhar sobre este não apenas como um conceito, mas como uma construção cultural, representando a dinâmica da própria escola, refletindo ações reais e, sem dúvida, levando-nos a instigantes reflexões.

Há certo sincretismo nas tendências pedagógicas na Educação Física. Vale aqui ressaltar que para Silva (2006 apud NEIRA; NUNES, 2014) toda tendência pedagógica se constitui em uma teoria curricular, reconhecendo que em cada momento da história o currículo se configurou como espaço privilegiado para setores nobres da sociedade manter a sua hegemonia. Para tal discussão, faz-se necessária uma apresentação das teorias curriculares da Educação Física do Brasil.

A primeira grande corrente é pautada nas teorias não críticas da Educação Física, mais conhecida como teoria tradicional. É representada pelas concepções desenvolvimentistas e psicomotoras, somando-se às voltadas para a aptidão física e saúde. Sua ênfase está na dimensão psicobiológica e biológica, destacando os trabalhos de Le Boulch (1987) e Tani et al. (1988), que direcionam os objetivos do componente para o desenvolvimento dos comportamentos motor, socioafetivo e cognitivo, ou para a melhoria das condições de saúde dos sujeitos da educação.

Na década de 1990, surgiram as tendências críticas de currículo que, a partir do movimento renovador da Educação Física, com fortes influências marxistas, "buscaram dar um novo norte para a Educação Física escolar" (BARBIERI et al., 2008, p. 223). Essa concepção tem clara representação na Educação Física nas obras de Soares et al. (1992) e Kunz (1996). Nesta corrente, o currículo visa à formação de um sujeito crítico e emancipado, utilizando-se dos elementos da cultura corporal de movimento como conhecimentos necessários à formação do cidadão com vistas à transformação social.

Segundo Nunes e Rúbio (2008), a concepção pós-crítica está pautada no conceito de 
diferença de Derrida (2003) e incorpora as contribuições de diversos campos teóricos como o multiculturalismo e os Estudos Culturais, visto que este movimento argumenta em favor da inclusão de todas as vozes, de todas as culturas, sendo uma tendência a ganhar força perante aqueles que almejam uma Educação Física com atos mais democráticos e acolhedores. Esta concepção concebe o componente como espaço de tematização das práticas corporais, tendo seus pilares fincados na cultura que o produz. Pesquisadores como Marcos Garcia Neira na Educação Física, Stuart Hall na antropologia social, e Gimeno Sacristán na Educação trazem significativas contribuições para esta concepção curricular.

Os documentos curriculares oficiais exercem papel de destaque na dinâmica que rege os Atos de Currículo da Educação Física nas escolas brasileiras, afinal, são textos preconizados pelo Ministério da Educação, representando aquilo que o Estado, através de especialistas educacionais, pensa para a educação nacional. Neira e Nunes (2014) afirmam com clareza que o currículo, em um sistema educacional nacional, tem em vista a formação de uma cultura hegemônica, promovendo uma prática não democrática e dominante.

No entanto, não basta apenas analisar a quais teorias curriculares estão atreladas os currículos das escolas, é preciso verificar os Atos de Currículo, ou seja, as ações pedagógicas da escola e suas relações a tudo que é planejado, organizado e executado pelos agentes educacionais (MACEDO, 2013). Mais importante que conceituar o currículo adotado pela unidade, é necessário compreender as influências que regem esta escolha. O que interessa na verdade é entender como essas influências têm sido representadas nos Atos de Currículo. Estudos realizados por Dittrich et al. (2000), Rosário e Darido (2005) e Impolcetto et al. (2007) se limitaram a analisar a escolha e a sistematização de conteúdos. Os resultados apontam para a permanência de propostas voltadas para o ensino esportivo.

Buscando a superação deste modelo de análise curricular e, dada a escassez de pesquisas voltadas para a análise dos atos de currículo em sua dimensão mais ampla, incluindo a análise das competências, objetivos e habilidades como aspectos essenciais no processo de ensino-aprendizagem, almejamos transcender. Desta vontade surge a motivação maior deste trabalho, afinal, a quais teorias curriculares estão vinculados os Atos de Currículo na Educação Física escolar do Ensino Fundamental II em escolas da rede pública em dois estados da região Nordeste? Para tanto, foram analisados os planos de ensino de duas escolas da rede pública de Simão Dias/SE e Paripiranga/BA, buscando identificar as principais influências teóricas.

\section{MÉTodo}

Este trabalho é caracterizado como uma pesquisa ${ }^{3}$ de corte qualitativo, sendo classificada como pesquisa explicativa documental. Para Gil (2007 citado por GERHARDT;

\footnotetext{
${ }^{3}$ Aprovada pelo Conselho de Ética do Centro Universitário UniAGES, processos nº 0144A-2016 e 0144B-2016.
} 
SILVEIRA, 2009), este tipo de pesquisa se preocupa em identificar os fatores que determinam ou contribuem para a ocorrência dos fenômenos, através de documentos, ou seja, explica o porquê das coisas por meio dos resultados oferecidos. Sendo assim, a partir da análise de Atos de Currículo, procurou-se explicar o porquê de sua sistematização, a que se deve, e a que está relacionado. Para tanto, foram recolhidos e analisados os planos de ensino do componente Educação Física do $6^{\circ}$ e do $9^{\circ}$ ano do Ensino Fundamental de duas escolas municipais ${ }^{4}$, uma (E1) situada em Simão Dias (SE) e outra (E2) em Paripiranga (BA). Como critério de inclusão, estes planos deveriam ter sido elaborados em 2016 para turmas do mesmo turno (matutino ou vespertino) e de responsabilidade do mesmo professor, a fim de que fosse possível observar a progressão dos conteúdos.

De acordo com Sá-Silva, Almeida e Guindani (2009), a análise documental se propõe a produzir ou reelaborar conhecimentos e criar novas formas de compreender os fenômenos. Seguindo as recomendações de Minayo (2007 apud GERHARDT; SILVEIRA, 2009), adotouse a análise por unidade temática. A pré-análise consistiu na organização do que seria analisado. Em seguida, partimos para a exploração do material e, por último, classificamos e agregamos os dados através de tabulação em eixos de análise temática: 1) relação Atos de Currículo da Educação Física e tendências curriculares, onde conteúdos, objetivos e competências do plano de ensino foram relacionados às tendências, tradicional, crítica e póscrítica; e 2) Atos de Currículo, possibilitaram a visualização das tendências curriculares predominantes em cada uma das categorias de análise dos planos de ensino.

Classificamos como tendência tradicional na Educação Física os planos representados nas concepções desenvolvimentista (TANI et al., 1996) e psicomotora (LE BOULCH, 1987), cujos Atos de Currículo atenderam a conteúdos, objetivos e competências que contemplaram a aprendizagem e o desenvolvimento motor ou as funções psicomotoras (coordenação óculomanual, lateralidade, percepção temporal, ajustamento postural e equilíbrio).

Já para as contribuições de análise no campo das tendências curriculares críticas foram utilizadas as concepções crítico-superadora da Educação Física (SOARES et al., 1992) e crítico-emancipatória (KUNZ, 1996). Classificamos como parâmetro de currículo crítico os atos que se propunham ao tratamento pedagógico da cultura corporal de movimento mediante perspectiva de leitura histórico-crítica, problematizando questões sociais.

Classificamos como currículo pós-crítico os atos que tematizaram as práticas corporais a partir das manifestações culturais onde a escola está inserida, por meio da vivência, ressignificação, aprofundamento e ampliação dos significados que lhes são atribuídos. Foram considerados os atos pós-críticos aqueles que, de alguma forma, buscaram inspirar-se no multiculturalismo, incluindo a valorização das práticas culturais da comunidade e problematizando os discursos que as perpassam.

\footnotetext{
${ }^{4}$ As equipes gestoras das unidades assinaram um Termo de Consentimento Livre e Esclarecido, autorizando a utilização dos documentos para fins da pesquisa.
} 
As informações coletadas foram confrontadas com o referencial teórico de cada tendência curricular cujos resultados subsidiaram a compreensão da sistematização dos Atos de Currículo da Educação Física no Ensino Fundamental II das escolas pesquisadas.

\section{Resultados E Discussão}

$\mathrm{Na}$ análise do plano do $6^{\circ}$ ano da escola E1 (QUADRO 1), os dados encontrados indicam atos em que predominam tendências curriculares tradicionais, uma vez que os conteúdos, objetivos e competências apontam para uma maior preocupação com os conhecimentos relacionados à aquisição e manutenção da saúde corporal e aprendizagem de habilidades motoras. A recorrência aos jogos, brincadeiras e esportes como instrumentos para o desenvolvimento de comportamentos revela o caráter funcionalista atribuído ao ensino da Educação Física.

Competências como "utilizar corretamente os materiais esportivos e didáticos, ampliar a capacidade de raciocínio lógico, reproduzir hábitos saudáveis de higiene e alimentação", representam uma distorção do objetivo geral do próprio plano que, por sua vez, aponta para atitudes de cooperação e solidariedade. No entanto, tornar-se cooperativo e solidário deve ser tarefa difícil quando a preocupação maior está voltada para utilização correta dos materiais, desenvolvimento do raciocínio lógico e aquisição de hábitos de higiene e de alimentação. Essas competências demonstram claramente a reprodução de hábitos e atitudes, características das tendências pedagógicas tradicionais.

Ainda neste mesmo plano, encontramos competências como "recriar as possibilidades práticas dos esportes, propor e produzir alternativas para experimentar os esportes", visivelmente alinhadas às teorias críticas, pois indicam a construção e desconstrução dos modelos tradicionais dos esportes. Desta forma, percebe-se o sincretismo entre tendências pedagógicas na elaboração destes atos, uma vez que não há coerência entre as competências e o objetivo geral, demonstrando uma desarmonia nestes atos curriculares. 
Quadro 1 - Relação Atos de Currículo da Educação Física

Plano de ensino $6^{\circ}$ - E1

\begin{tabular}{|l|}
\hline \multicolumn{2}{|c|}{ ATOS DE CURRÍCULO } \\
\hline \multicolumn{1}{|c|}{ CONTEÚDOS } \\
\hline UNIDADE I \\
Importância da Educação Física (aspectos gerais e a importância do movimento). \\
\hline Atletismo (corridas, saltos, arremessos e lançamentos). \\
\hline UNIDADE II \\
\hline Benefícios da Atividade Física. Higiene e Hábitos alimentares. \\
\hline $\begin{array}{l}\text { UNIDADE III } \\
\text { Handebol (características básicas, regras e fundamentos). }\end{array}$ \\
\hline $\begin{array}{l}\text { UNIDADE IV } \\
\text { Conhecimentos sobre o corpo: As partes do corpo e os exercícios físicos com suas possibilidades e } \\
\text { limitações. }\end{array}$ \\
\hline \\
\hline $\begin{array}{l}\text { Proporcionar o desenvolvimento integral do aluno, através de jogos, brincadeiras e esportes, bem } \\
\text { como com a inserção de hábitos saudáveis no cotidiano. Com isso, buscando adotar uma atitude } \\
\text { cooperativa e solidária, explorando a criatividade e diversificando a dinâmica das ações motoras e } \\
\text { das relações sociais. }\end{array}$ \\
\hline \\
\hline Praticar com autonomia os esportes escolhidos; \\
\hline Compreender a importância da relação interpessoal; \\
\hline Identificar, debater e utilizar estratégias para situações problemáticas; \\
\hline Utilizar corretamente os materiais esportivos e didáticos; \\
\hline Ampliar a capacidade de raciocínio lógico; \\
\hline Respeitar os colegas e adversários; \\
\hline Organizar e relacionar ideias novas ao cotidiano escolar; \\
\hline Recriar as possibilidades pratica dos esportes; \\
\hline Propor e produzir alternativas para experimentar os esportes; \\
\hline Reproduzir hábitos saudáveis de higiene e alimentação; \\
\hline Entender a importância do exercício físico para a vida; \\
\hline Vivenciar diversas práticas corporais; \\
\hline Criar um ambiente de alegria e descontração. \\
\hline
\end{tabular}

O plano de ensino do $6^{\circ}$ ano (QUADRO 2) da E2 apresenta conteúdos, em sua maioria, voltados para aspectos históricos e epistemológicos da Educação Física e dos esportes. Além disso, propõe a inclusão de pessoas com deficiência, indiciando certo estímulo para a problematização de questões sociais.

A escolha dos Atos de Currículo representados nestes conteúdos leva a crer que se trata de uma tentativa de discutir aspectos histórico-críticos da Educação Física e as suas produções culturais. Para Azevedo e Shigunov (2000), nas concepções críticas busca-se compreender os conteúdos da Educação Física e as possibilidades de sua apropriação crítica, valorizando a contextualização dos fatos e o resgate histórico.

O objetivo principal deste plano é "compreender e saber identificar a Educação Física como fato histórico contextualizado nas diversas culturas, conhecendo respeitando e podendo observar as produções presentes no entorno [...]”. Ao analisar como tal se apresenta, harmonizase com a escolha dos conteúdos, percebe-se aqui a inspiração em uma Educação Física 
reformada, o que leva à predominância de conteúdos, objetivo e competências que discutem a importância histórica do componente e de suas práticas como produções humanas, expressas na tentativa de trazer à tona discussões de cunho social.

Entretanto, fugindo à tônica da perspectiva crítica, o documento contempla também uma competência que alude aos currículos tradicionais da Educação Física que é "perceber e valorizar que os jogos cooperativos também são atividades físicas, que servem como fatores que contribuem para a saúde e a qualidade de vida". Assim, demonstram certa crença nas teorias tradicionais, onde se acredita que a prática de jogos, atividades e exercícios físicos, por si só, conduzem aos benefícios, à saúde e a tal qualidade de vida.

Quadro 2 - Relação Atos de Currículo da Educação Física e tendências curriculares Plano de ensino $6^{\circ}$ - E2

\begin{tabular}{|c|}
\hline ATOS DE CURRÍCULO \\
\hline $\begin{array}{l}\text { UNIDADE I } \\
\text { História da Educação Física; }\end{array}$ \\
\hline Contexto atual e finalidades da Educação Física; \\
\hline Jogos populares; \\
\hline Jogos e brincadeiras. \\
\hline $\begin{array}{l}\text { UNIDADE II } \\
\text { Educação Física de Inclusão; }\end{array}$ \\
\hline Jogos Cooperativos. \\
\hline $\begin{array}{l}\text { UNIDADE III } \\
\text { História do Futebol; }\end{array}$ \\
\hline História do Handebol; \\
\hline $\begin{array}{l}\text { UNIDADE IV } \\
\text { História do voleibol; }\end{array}$ \\
\hline História do Basquete. \\
\hline OBJETIVO GERAL \\
\hline $\begin{array}{l}\text { Compreender e saber identificar a Educação Física como fato histórico contextualizado nas } \\
\text { diversas culturas, conhecendo respeitando e podendo observar as produções presentes no entorno, } \\
\text { assim como as demais do patrimônio cultural e do universo natural, identificando a existência de } \\
\text { diferenças nos padrões físicos e da saúde; }\end{array}$ \\
\hline COMPETÊNCIAS \\
\hline Conhecer melhor a história da Educação Física para perceber a sua importância; \\
\hline Perceber a importância do seu contexto e a sua utilidade na nossa vida. \\
\hline Identificar a importância dos jogos populares e as suas diferenças; \\
\hline Analisar a importância da Educação Física de inclusão para as pessoas com qualquer deficiência; \\
\hline $\begin{array}{l}\text { Perceber e Valorizar que os Jogos Cooperativos também são atividades físicas, que servem como } \\
\text { fatores que contribuem para a saúde e a qualidade de vida. }\end{array}$ \\
\hline Analisar a importância da Educação Física de inclusão para as pessoas com qualquer deficiência; \\
\hline Compreender melhor, como os homens utilizavam os tipos de bolas em suas vidas; \\
\hline Perceber a importância do handebol, e a relação dele com o nosso cotidiano. \\
\hline Verificar as realizações feitas pelos jogadores de voleibol no Brasil e em outros países \\
\hline
\end{tabular}

Ao analisar os Atos de Currículo do plano do $9^{\circ}$ ano da E1 (QUADRO 3), é possível perceber novamente a preocupação com o desenvolvimento integral através da utilização de ferramentas que se valem do trabalho psicomotor ou de finalidades desenvolvimentistas, 
demonstrando influência das perspectivas tradicionais da Educação Física.

Além disso, parece que a escolha dos conteúdos demonstra a preocupação com o desenvolvimento dos aspectos técnicos e biologicistas: "Basquetebol (características básicas, regras e fundamentos); Sedentarismo (características básicas); Voleibol (regras e fundamentos)". O objetivo geral também apresenta características que visam potencializar o desenvolvimento motor dos alunos: "Proporcionar o desenvolvimento integral do aluno, através de jogos, brincadeiras, adicionando elementos de coordenação motora básica; correr, saltar, equilibrar, girar, rolar e elementos de coordenação motora específica; lateralidade, arremessar, espaço/ temporal [...]". As competências encontradas neste plano são idênticas aos do plano de ensino do $6^{\circ}$ ano (QUADRO 1) da mesma escola, evidenciando a ausência de progressão na complexidade dos conteúdos trabalhados. Essa repetição pode tornar as aulas enfadonhas, e desencorajar o aluno a aprofundar conhecimentos acerca das práticas corporais.

Quadro 3 - Relação Atos de Currículo da educação física e tendências curriculares

Plano de ensino $9^{\circ}$ - E1

\begin{tabular}{|c|}
\hline ATOS DE CURRÍCULO \\
\hline $\begin{array}{l}\text { UNIDADE I } \\
\text { História da Educacão Física; }\end{array}$ \\
\hline Contexto atual e finalidades da Educação Física; \\
\hline Jogos populares; \\
\hline Jogos e brincadeiras. \\
\hline $\begin{array}{l}\text { UNIDADE II } \\
\text { Educação Física de Inclusão; }\end{array}$ \\
\hline Jogos Cooperativos. \\
\hline $\begin{array}{l}\text { UNIDADE III } \\
\text { História do Futebol; }\end{array}$ \\
\hline História do Handebol; \\
\hline $\begin{array}{l}\text { UNIDADE IV } \\
\text { História do voleibol; }\end{array}$ \\
\hline História do Basquete. \\
\hline OBJETIVO GERAL \\
\hline $\begin{array}{l}\text { Compreender e saber identificar a Educação Física como fato histórico contextualizado nas diversas } \\
\text { culturas, conhecendo respeitando e podendo observar as produções presentes no entorno, assim como } \\
\text { as demais do patrimônio cultural e do universo natural, identificando a existência de diferenças nos } \\
\text { padrões físicos e da saúde; }\end{array}$ \\
\hline COMPETÊNCIAS \\
\hline Conhecer melhor a história da Educação Física para perceber a sua importância; \\
\hline Perceber a importância do seu contexto e a sua utilidade na nossa vida. \\
\hline Identificar a importância dos jogos populares e as suas diferenças; \\
\hline Analisar a importância da Educação Física de inclusão para as pessoas com qualquer deficiência; \\
\hline $\begin{array}{l}\text { Perceber e Valorizar que os Jogos Cooperativos também são atividades físicas, que servem como } \\
\text { fatores que contribuem para a saúde e a qualidade de vida. }\end{array}$ \\
\hline Analisar a importância da Educação Física de inclusão para as pessoas com qualquer deficiência; \\
\hline Compreender melhor, como os homens utilizavam os tipos de bolas em suas vidas; \\
\hline Perceber a importância do handebol, e a relação dele com o nosso cotidiano. \\
\hline Verificar as realizações feitas pelos jogadores de voleibol no Brasil e em outros países \\
\hline Analisar as diferenças entre o basquete e os outros tipos de jogos \\
\hline
\end{tabular}


O plano de ensino do $9^{\mathrm{a}}$ ano da escola E2 apresenta conteúdos de aspectos biologicistas apenas, apesar de estar relacionada de forma harmoniosa com os objetivos contidos nas tendências tradicionais curriculares da Educação Física (QUADRO 4). Conhecimentos como "Nutrição Aplicada à Educação Física Escolar" concernem características voltadas ao desenvolvimento da aptidão física e da saúde. Conforme Guedes e Guedes (1993 apud AZEVEDO; SHIGUNOV, 2000, p. 2) "a aptidão física relacionada à saúde abriga aqueles aspectos da função fisiológica, que oferecem alguma proteção aos distúrbios orgânicos provocados por um estilo de vida sedentário". Assim, o principal objetivo seria fomentar uma Educação Física atenta à prevenção de patologias e distúrbios da atualidade. A preocupação com a saúde remonta às teorias tradicionais do currículo, também chamadas de neohigienismo, uma vez que se pautam unicamente em conhecimentos técnicos e superficiais acerca do conceito de saúde.

Quadro 4 - Relação Atos de Currículo da educação física e tendências curriculares Plano de ensino $9^{\circ}$ - E2

\begin{tabular}{|c|}
\hline ATOS DE CURRÍCULO \\
\hline $\begin{array}{l}\text { UNIDADE I } \\
\text { Sistema Hormonal; } \\
\text { Sistema Reprodutor: } \\
\text { - Masculino; } \\
\text { - Feminino. }\end{array}$ \\
\hline $\begin{array}{l}\text { UNIDADE II } \\
\text { Nutrição Aplicada a Educação Física Escolar; } \\
\text { As Lutas. }\end{array}$ \\
\hline $\begin{array}{l}\text { UNIDADE III } \\
\text { Atividades Rítmicas e Expressivas (Danças); } \\
\text { Ginástica. }\end{array}$ \\
\hline $\begin{array}{l}\text { UNIDADE IV } \\
\text { Primeiros Socorros. }\end{array}$ \\
\hline
\end{tabular}

Participar de atividades corporais, estabelecendo relações equilibradas e construtivas com os outros, reconhecendo e respeitando características físicas, e entender melhor o funcionamento dos sistemas do nosso corpo, e a relação da saúde com a alimentação saudável e os diversos tipos de esportes e atividades físicas praticadas de forma consciente e contínua.

Entender melhor a função dos hormônios em nosso corpo.

Perceber que o sistema reprodutor tem muita importância e influência em nossa saúde;

Verificar o funcionamento dos órgãos responsáveis pela reprodução masculina;

Compreender quais partes do nosso corpo forma o sistema reprodutor feminino e a sua importância.

Compreender que é muito importante se alimentar de forma correta, até mesmo nas escolas para ter uma boa saúde;

Diferenciar os diversos tipos de lutas, existentes em todo o planeta, e suas características principais que as tornam importantes no auxílio da saúde.

Entender melhor como são realizadas as atividades rítmicas e expressivas;

Diferenciar os tipos de ginástica dos outros tipos de esportes, e as suas classificações.

Compreender como são realizados os primeiros socorros, percebendo quando realmente é necessário e como deve ser feito para ajudar o próximo sem prejudicá-lo.

O objetivo geral e as competências seguem o mesmo caminho, com traços e intenções 
voltadas para a fixação de um estilo de vida saudável, neste fragmento retirado do objetivo geral é possível visualizar tais intenções: “[...] reconhecendo e respeitando características físicas, e entender melhor o funcionamento dos sistemas do nosso corpo, e a relação da saúde com a alimentação saudável e os diversos tipos de esportes e atividades físicas praticados de forma consciente e continuas [...]" que, para Nunes e Rúbio (2008) são características de uma Educação Física pautada nas tendências tradicionais.

Neste ponto, faz-se necessário ressaltar que o cuidado excedido nestes planos de ensino, que demonstram preocupação com a aptidão física e saúde do indivíduo, alinham-se a algumas propostas oficiais do componente, como os PCN'S (BRASIL, 1998). A Educação Física se constitui num interminável arcabouço de práticas e temáticas corporais a serem exploradas, com diferentes objetivos que vão da apropriação de determinadas práticas culturais, passando pela ludicidade intrínseca às diferentes práticas, até o cuidado com a saúde e qualidade de vida.

No entanto, o que foi possível visualizar até o presente momento é uma forte influência das tendências curriculares tradicionais. Com exceção do plano do $6^{\circ}$ ano da escola E2 na qual se apresenta certo hibridismo, os demais se encontram pautados em aspectos psicobiológicos, preocupando-se mais com o desenvolvimento motor, aptidão física e cuidados com o corpo.

\section{ATOS DE CURRÍCULO: tendências curriculares predominantes}

Neste eixo temático, o objetivo foi categorizar os planos de ensino, conforme os Atos de Currículo, identificando a inclinação às tendências curriculares dominantes.

Quadro 5 - Atos de Currículo (conteúdos): tendências curriculares predominantes

\begin{tabular}{|l|c|}
\hline \multicolumn{1}{|c|}{ ESCOLA / PLANO DE ENSINO } & $\begin{array}{c}\text { TENDÊNCIA CURRICULAR } \\
\text { PREDOMINANTE }\end{array}$ \\
\hline $\mathrm{E} 1.6^{\circ} \mathrm{ANO}$ & TCT \\
\hline $\mathrm{E} 2.6^{\circ} \mathrm{ANO}$ & TCC \\
\hline $\mathrm{E} 1.9^{\circ} \mathrm{ANO}$ & TCT \\
\hline $\mathrm{E} 2.9^{\circ} \mathrm{ANO}$ & TCT \\
\hline
\end{tabular}

Tendência curricular tradicional (TCT) / Tendência curricular crítica: (TCC).

Analisando os dados descritos no Quadro 5, parece haver um predomínio das tendências curriculares tradicionais na escolha e organização dos conteúdos nos documentos pesquisados, isso é visível a partir do momento que três dos quatro planos de ensino apresentam em seus conteúdos concepções tradicionais (psicomotora, desenvolvimentista, educação para a saúde e esportivista) e apenas uma proposta crítica. Assim, os resultados encontrados neste trabalho se assemelham aos obtidos por Rosário e Darido (2005) que constataram que da $5^{\circ}$ a $8^{a}$ série do Ensino Fundamental o esporte de forma inegável ainda é o principal conteúdo da Educação Física. Podemos identificar, de acordo com a visão de Vasconcellos (2011), aspectos de uma tendência curricular neo-tecnicista centrada no 
desenvolvimento de habilidades através de conteúdos dominantes.

Verificou-se ainda que a maioria dos professores organizam os seus planos baseados principalmente na dimensão procedimental, priorizando o saber fazer. Além disto, podemos perceber certa dificuldade no entendimento do que seria competência, da forma como os professores a colocam nos planos, elas podem ser classificadas como habilidades, pois descrevem procedimentos e ações. Enquanto uma proposta baseada em competências consiste na preocupação com a autonomia do aluno, que através das manifestações culturais surgem a partir das relações transversais de dois ou mais saberes. Tal atitude demonstra a necessidade de maior apropriação do conceito de competência e conhecimento dos fenômenos vivenciados dentro e fora da escola, como alicerce das relações de conteúdos, competências e habilidades para a formulação dos planos de ensino.

Para Neira e Nunes (2009) já que o currículo está inserido em limites dentro do espaçotempo, para elaborar uma proposta curricular, torna-se necessário selecionar uma parcela do capital cultural disponível na sociedade para ser partilhado e socializado com o público escolar. Tal seleção, no entanto, não deve servir para reforçar os valores dominantes da sociedade, mas fazer com que o individuo se insira nas discussões e aproprie-se dos saberes culturais e das questões pertinentes à vida social da qual é pertencente, desenvolvendo competências.

Quadro 6 - Atos de Currículo (objetivo geral): tendências curriculares predominantes

\begin{tabular}{|c|c|}
\hline ESCOLA / PLANO DE ENSINO & $\begin{array}{c}\text { TENDÊNCIA CURRICULAR } \\
\text { PREDOMINANTE }\end{array}$ \\
\hline $\mathrm{E} 1.6^{\circ} \mathrm{ANO}$ & TCT \\
\hline $\mathrm{E} 2.6^{\circ} \mathrm{ANO}$ & TCC \\
\hline $\mathrm{E} 1.9^{\circ} \mathrm{ANO}$ & TCT \\
\hline $\mathrm{E} 2.9^{\circ} \mathrm{ANO}$ & TCT \\
\hline
\end{tabular}

Tendência curricular tradicional: (TCT) / Tendência curricular crítica: (TCC).

Ao analisar os objetivos, segue-se como resultado a similaridade encontrada ao falarmos de conteúdos, isto porque novamente a única exceção está no plano de ensino do $6^{\circ}$ ano da escola E2 que, diferentemente dos outros planos analisados, possui Atos de Currículo com predominância das tendências críticas.

No entanto, os outros três planos apresentam objetivos com predomínio das tendências tradicionais, sendo possível verificar a maior preocupação com aspectos motores, com os procedimentos do fazer. Desta forma, para estes, as demais aprendizagens possibilitadas pela Educação Física ficam relegadas a um papel secundário e surgem por meio do currículo oculto. Sendo assim, mais uma vez os procedimentos são exacerbados em detrimento dos reais aspectos e significados culturais das práticas corporais. Os resultados encontrados demonstram a forte influência tradicional de currículo por detrás destes objetivos, que "ao aceitarem mais facilmente o status quo, os conhecimentos e os saberes dominantes, acabaram por se concentrar em questões técnicas" (SILVA, 2011, p. 16). Concluímos que esta 
constatação demonstra que a Educação Física, fincada nestes objetivos, limita-se à manutenção do status quo, afinal reforça conceitos e ideais dominantes de sociedade, onde o maior objetivo da Educação Física é unicamente o cuidado com o corpo em seus aspectos biológicos.

Quadro 7 - Atos de Currículo (competências): tendências curriculares predominantes

\begin{tabular}{|c|c|}
\hline ESCOLA / PLANO DE ENSINO & $\begin{array}{c}\text { TENDENCIA CURRICULAR } \\
\text { PREDOMINANTE }\end{array}$ \\
\hline $\mathrm{E} 1.6^{\circ} \mathrm{ANO}$ & TCT \\
\hline $\mathrm{E} 2.6^{\circ} \mathrm{ANO}$ & TCC \\
\hline $\mathrm{E} 1.9^{\circ} \mathrm{ANO}$ & TCT \\
\hline $\mathrm{E} 2.9^{\circ} \mathrm{ANO}$ & TCT \\
\hline
\end{tabular}

Tendência curricular tradicional: (TCT) / Tendência curricular crítica: (TCC).

$\mathrm{Na}$ análise das competências, faz-se necessário discutir a noção destas apresentadas nos planos de ensino. Fica evidente o equívoco entre o que seriam competências e habilidades, visto que há um conflito entre o saber fazer designando noções adquiridas de práticas em detrimento do saber ser (COSTA, 2005). Portanto, o conceito de competências "engloba uma série de qualidades pessoais como ordem, método, precisão, rigor, polidez, autonomia, imaginação, iniciativa, adaptabilidade" (STROOBANTS, 2002 apud COSTA, 2005, p. 9). Assim sendo, as competências previstas nos documentos analisados trazem o passo a passo do como fazer apenas, descaracterizando demais elementos subjetivos importantes para o processo do saber ser.

Nos planos de ensino que deram suporte a esta pesquisa, as competências assumem caráter de habilidades, pois apontam apenas para sequências do que saber, do que fazer, e do que adquirir. Desta forma, foi possível verificar que a maioria delas está direcionada aos aspectos do fazer através de ações pragmáticas possibilitadas por meio dos esportes como podemos visualizar neste exemplo: "praticar com autonomia os esportes escolhidos; utilizar corretamente os materiais esportivos e didáticos; recriar as possibilidades prática dos esportes; propor e produzir alternativas para experimentar os esportes; reproduzir hábitos saudáveis de higiene e alimentação".

Tal como expostas nos documentos, estas competências têm representado apenas ações em sequência pré-determinada, representam ideias de uma pedagogia neoliberal que propicia através do currículo tradicional o aprendizado mecanizado. A mera reprodução vem apenas dando força a práticas pedagógicas tradicionais, caracterizadas por conteúdos excludentes, e objetivos quase sempre pouco significativos.

Assim sendo, estes dados nos permitem dizer que os conteúdos continuam sendo os mesmos, os objetivos refletem ideias tão superficiais que remetem à prática do fazer pelo fazer, onde os procedimentos são mais importantes do que os conceitos e valores, as competências caminham num mesmo sentido e ajudam a fomentar tal hegemonia, pois demonstram mais preocupação no fazer, do que no quê e para que fazer. Percebe-se, além 
disso, os sincretismos pedagógicos que são caracterizados principalmente pela desarmonia entre competências e objetivos e que resultam do choque entre diferentes teorias pedagógicas dentro do mesmo escopo de competências, fato este que dificulta a percepção de qual tipo de sujeito pretende-se formar através destes atos.

\section{CONSIDERAÇÕES FINAIS}

Os Atos de Currículo analisados neste trabalho demonstram uma pequena amostra daquilo que tem sido encontrado nos planejamentos de professores de Educação Física no polígono das secas nas cidades de Simão Dias - SE e Paripiranga - BA.

Ao iniciar esta análise tínhamos em mente a dificuldade de classificar as tendências curriculares às quais os Atos de Currículo da Educação Física no Ensino Fundamental II destas escolas estavam vinculados. Dada a escassez de trabalhos neste viés, buscamos na literatura trabalhos que analisavam a escolha de conteúdos e, assim, os resultados sobre os conteúdos escolhidos assemelham-se aos de Rosário e Darido (2005) e Impolcetto et al. (2007). Em relação aos conteúdos e objetivos, encontramos um bom parâmetro no trabalho de Dittrich et al. (2000) e os resultados novamente apresentaram similaridades.

As hipóteses foram assim confirmadas, pois com a análise dos Atos de Currículo da Educação Física baseada nos planos de ensino dos professores foi possível perceber elaborações confusas, com conteúdo, objetivos e competências simplistas, concernindo à Educação Física escolar um papel reducionista de fomentar corpos biologicamente harmoniosos para o lazer, o trabalho e aprendizagem.

Os conteúdos dominantes representados pelos esportes coletivos, visualizados nos estudos acima citados, corroboram com os achados deste trabalho. Os objetivos e competências seguem no mesmo caminho dos conteúdos, privilegiando os esportes coletivos e condicionando o corpo ao trabalho técnico reprodutivo através deles. Ainda sobre as competências, parece-nos que existem equívocos conceituais, afinal a escrita de muitas competências descreviam ações e procedimentos que poderiam caracterizar habilidades, além do que apresentam objetivos que não possuem a complexidade exigida em uma competência. Desta forma, parece haver certa preocupação nestes Atos de Currículo com os aspectos biológicos do movimento, remetendo a concepções desenvolvimentistas e psicomotricistas.

O que se visualizou foram Atos de Currículo ainda mais tradicionais ao avançar a etapa. Ou seja, no $9^{\circ}$ ano, às portas do Ensino Médio, foram percebidos Atos de Currículo tradicionais, diferentemente do que os do $6^{\circ}$ ano. Uma rara exceção foi encontrada em apenas um dos planos analisados, onde, diferente dos demais, tinha uma elaboração firmada em concepções críticas, respingando um suspiro para aqueles que defendem uma Educação Física que lute contra a dominação da classe burguesa sobre os demais.

No entanto, não encontramos subsídios que pudessem relacionar os Atos de Currículo 
aqui analisados às tendências curriculares pós-críticas, isso nos faz levantar a hipótese de que os documentos curriculares norteadores para a educação básica não têm sido contemplados nestes atos, tampouco os professores parecem estar atentos ou preocupados com a inclusão de teorias pós-críticas no projeto de curso.

Acreditamos, no entanto, que os Atos de Currículo pensados no viés pós-critico devem ser pensados à luz das relações culturais que envolvem a dinamicidade das relações entre professor, alunos e comunidade. Estes deveriam entrelaçar-se para compor os Atos de Currículo do ano letivo, viabilizando, assim, aulas de Educação Física includentes e democráticas, utilizando da cultura local como norte para elaboração dos Atos.

Ainda assim, acreditamos ser necessário ocupar outros lugares para obter outras perspectivas, mesmo reconhecendo a possibilidade de planos de ensino baseados em outras teorias que podem ser coerentes com seus conteúdos, objetivos e competências, o que não observamos no presente estudo. Ratificamos que os planos de ensino apresentam certo hibridismo sobre qual tendência pedagógica foram pautadas as suas ações, não apresentando coerência entre os seus elementos. Assim, reafirmamos que estes documentos devem estar coerentes numa linha pedagógica que leve claramente a que tipo de sujeito se quer formar, desta forma, as propostas pós-críticas tem demostrado maiores possibilidades para conciliar as necessidades de aprendizagem, os objetos de estudo da Educação Física Escolar e o contexto sociocultural cuja escola está inserida.

Conclui-se, portanto, que os resultados encontrados neste trabalho apontam para a necessidade de transcendência na elaboração de Atos de Currículo na Educação Física, e de maior aprofundamento na análise destes Atos, despertando nos professores maior responsabilidade ao pensar o currículo. Assim, faz-se o convite a todos aqueles entusiastas que acreditam numa Educação Física Escolar significativa, preocupada com os signos e as construções culturais, e que seja capaz de construir e transformar conhecimentos pertinentes e necessários às diferentes realidades escolares, independentemente das teorias de apoio, desde que coerentes com o sujeito se pretende formar.

\section{REFERÊNCIAS}

AZEVEDO, Edson; SHIGUNOV, Viktor. Reflexões sobre as Abordagens Pedagógicas em Educação Física. Dissertação (Mestrado em Educação Física)-Centro de Desportos, Universidade Federal de Santa Catarina, Florianópolis, 2000.

BARBIERI, Aline Fabiane et al. Abordagens, concepções e perspectivas de educação física quanto à metodologia de ensino nos trabalhos publicados na Revista Brasileira de Ciências do Esporte (RBCE) em 2009. Revista Motrivivência, n. 31, p. 223-240 dez. 2008. Disponível em: <https://periodicos.ufsc.br/index.php/motrivivencia/article/view/14106>. 
BRASIL. Secretaria de Educação Fundamental. Parâmetros curriculares nacionais: educação física. Brasília: MEC/SEF, 1998.

COSTA, Thais Almeida. A noção de competência enquanto princípio de organização curricular. Revista Brasileira de Educação, Rio de Janeiro, n. 29, maio/ago. 2005. Disponível em: 〈http://www.scielo.br/scielo.php?pid=S1413-24782005000200005\&script=sci_abstract $>$.

DERRIDA, Jacques. La différence in Marges de la Philosophie. Paris: Les Editions de Minuit, 2003. Collection «Critique». Disponível em:

<http://www.leseditionsdeminuit.fr/livre-Marges_de_la_philosophie-2029-1-1-0-1.html>.

DITTRICH, Douglas Danilo et al. Educação Física escolar: cultura, currículo e conteúdo. Revista Educar, Curitiba, n. 16, p. 81-98, 2000. Disponível em:

<http://www.scielo.br/scielo.php?script=sci_arttext\&pid=S0104-40602000000200006>.

GERHARDT, Tatiana Engel; SILVEIRA, Denise Tolfo (Org.) Métodos de pesquisa. Porto Alegre: Editora da UFRGS, 2009. Série Educação a Distância. Disponível em:

<http://www.ufrgs.br/cursopgdr/downloadsSerie/derad005.pdf>.

IMPOLCETTO, Fernanda Moreira et al. Educação Física no ensino fundamental e médio: a sistematização dos conteúdos na perspectiva de docentes universitários. Revista Mackenzie de Educação Física e Esporte, v. 6, n. 1, p. 89-109, 2007. Disponível em:

<http://editorarevistas.mackenzie.br/index.php/remef/article/view/1285>.

KUNZ, Elenor. Transformação Didático-Pedagógica do Esporte. 7. ed. Porto Alegre: Unijuí, 1996.

LE BOULCH, Jean. Educação Psicomotora a Psicocinética na idade escolar. Porto Alegre: Artmed, 1987.

MACEDO, Roberto Sidnei. Currículo: campo, conceito e pesquisa. 6 ed. Petrópolis-RJ: Vozes, 2013.

NEIRA, Marcos Garcia. O currículo cultural da Educação Física: uma resposta aos dilemas da contemporaneidade. Revista Linhas. Florianópolis, v. 16, n. 31, p. 276-304, maio/ago. 2015. Disponível em:

<http://www.revistas.udesc.br/index.php/linhas/article/view/1984723816312015276>.

NEIRA, Marcos Garcia; NUNES, Mário Luiz Ferrari. Pedagogia da Cultura Corporal críticas e alternativas. 2. ed. São Paulo: Phorte, 2014.

NEIRA, Marcos Garcia; NUNES, Mário Luiz Ferrari. Teorização curricular e Educação Física. In: . Educação Física, currículo e cultura. São Paulo: Phorte, 2009. 
NUNES, Mário Luiz Ferrari. RÚBIO, Katia. O(s) currículo(s) da Educação Física e a constituição da identidade de seus sujeitos. Currículo sem Fronteiras, v. 8, n. 2, p.55-77, jul./dez. 2008. Disponível em:

<https://www.researchgate.net/publication/237636225_OS_CURRICULOS_DA_EDUCACA O_FISICA_E_A_CONSTITUICAO_DA_IDENTIDADE_DE_SEUS_SUJEITOS>.

ROSÁRIO, Luiz Fernando Rocha; DARIDO, Suraya Cristina. A sistematização dos conteúdos da educação física na escola: a perspectiva dos professores experientes. Revista Motriz, Rio Claro, v. 11, n. 3, p. 167-178, set./dez. 2005. Disponível em:

<http://www.rc.unesp.br/ib/efisica/motriz/11n3/10LRF.pdf>.

SÁ-SILVA, Jackson Ronie; DE ALMEIDA, Cristóvão Domingues; GUINDANI, Joel Felipe. Pesquisa documental: pistas teóricas e metodológicas. Revista Brasileira de História \& Ciências Sociais, v. 1, n.1, julho. 2009. Disponível em:

<https://www.rbhcs.com/rbhcs/article/view/6/pdf>.

SILVA, Tomaz. Tadeu. Documentos de identidade: uma introdução às teorias do currículo. Belo Horizonte: Autêntica, 2011. Disponível em:

<https://www.revistas.ufg.br/fef/article/view/83/2679>.

SOARES, Carmen Lúcia et al. Metodologia do ensino da educação física. São Paulo: Cortez, 1992.

TANI, Go et al. Educação Física Escolar: fundamentos de uma abordagem desenvolvimentista. São Paulo: EPU, 1988.

VASCONCELlOS, Celso dos Santos. Currículo: a atividade humana como principio educativo. São Paulo: Libertad, 2011. 